\title{
Predictors and outcome of acute kidney injury after non-cardiac paediatric surgery
}

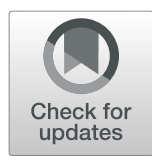

Taiwo Akeem Lawal ${ }^{1^{*}}$ (D), Yemi Raheem Raji ${ }^{2}$, Samuel Oluwole Ajayi ${ }^{2}$, Adebowale Dele Ademola ${ }^{3}$, Adeyinka Francis Ademola ${ }^{4}$, Omobolaji O. Ayandipo ${ }^{4}$, Tinuola Adigun ${ }^{5}$, Olakayode Olaolu Ogundoyin?', Dare Isaac Olulana ${ }^{1}$, Adanze Onyenonachi Asinobi ${ }^{3}$ and Babatunde Lawal Salako ${ }^{2}$

\begin{abstract}
Background: It is necessary to define the problem of acute kidney injury (AKI) after non-cardiac surgery in order to design interventions to prevent AKI. The study aimed to evaluate the occurrence, determinants and outcome of AKI among children undergoing general (non-cardiac) surgery.

Methods: This was a prospective cohort study of patients aged $\leq 15$ years who had general surgery over 18 months period at a tertiary hospital in Nigeria. AKI was evaluated at 6 and $24 \mathrm{~h}$ and within 7 days of surgery. Data were analysed using SPSS version 21.

Results: A total of 93 patients were studied with age ranging from 3 days to 15 years (median $=4$ years). AKI occurred within $24 \mathrm{~h}$ of surgery in $32(34.4 \%)$ and cumulatively over 7 days in 33 (35.5\%). Patients who had sepsis were nearly four times as likely as others to develop perioperative $A K I(O R=3.52,95 \% \mathrm{Cl} 1.21,10.20, p=0.021)$. Crude mortality rate was 12.1\% (4/33); no mortality was recorded among those without AKI, $p=0.014$.

Conclusion: Perioperative AKI occurred in 35.5\% of children who underwent general (non-cardiac) surgery. Patients who had sepsis were four times more likely than others to develop AKI. Mortality was documented only in patients who had AKI.
\end{abstract}

Keywords: Acute kidney injury, Paediatric, Perioperative, Non-cardiac surgery

\section{Background}

Acute kidney injury (AKI) may occur after surgery, and it is a major perioperative event. AKI is a manifestation of renal dysfunction, which is associated with accumulation of nitrogenous wastes, disturbance of acid, base and electrolytes and disequilibrium in handling of fluids by the body tissues and organs [1]. AKI presents an enormous burden to patients and the healthcare system and prevention, when possible, has been advocated by the International Society of Nephrology [2]. The reported mortality from AKI in children range from 1.2 to $50.7 \%$ [3-6], and it is associated with prolonged hospital stay and need for renal replacement therapy $[3,5,6]$.

\footnotetext{
* Correspondence: taiwo.lawal@hotmail.com

${ }^{1}$ Division of Paediatric Surgery, Department of Surgery, College of Medicine, University of Ibadan, PMB 5017, Ibadan 200212, Nigeria

Full list of author information is available at the end of the article
}

The patterns and prevalences of AKI differ between developing countries that are largely in the low- to middle-income categories and the developed ones in high-income group. As much as 73 to $80 \%$ of AKI occur in the community in low- and middle-income countries (LMICs), compared to $20 \%$ in high-income countries (HICs) $[4,6,7]$. A perioperative risk factor was identified in $4 \%$ to $6 \%$ of children with AKI in LMICs and in as much as $27 \%$ in HICs [4]. The risk factors for community-acquired AKI in children are largely related to public health infrastructural challenges such as sanitation, infectious diseases, and diarrhoeal diseases [4], but this cannot be said of perioperative AKI, where the variables surrounding the development of AKI are largely related to the characteristics and severity of the disease and its management in respective healthcare settings.

It is estimated that $11 \%$ to $19 \%$ of children from LMICs have a surgical need $[8,9]$. This implies that a large number of the paediatric population is likely to be exposed to 
major surgery. AKI has been extensively studied after paediatric cardiac surgery where prevalence of $9.6 \%$ to $65 \%$ has been recorded [10]. Conversely, there is a paucity of published literature on the occurrence of AKI in paediatric patients who underwent general (non-cardiac) surgical procedures. Furthermore, the profile of paediatric patients who had general surgery in sub-Saharan Africa, although often very young and with congenital malformations in about a third of cases, largely non-cardiac [11], are not as ill as patients who undergo cardiac surgery. The stress of surgery is an additional factor to consider compared to non-critically ill patients admitted to paediatric wards. The information gap makes it difficult to appreciate the extent of the problems of perioperative AKI, especially outside Paediatric Intensive Care Unit settings. It is also easier to design interventions to prevent AKI if the targeted risk factor subset is homogenous [12], in this instance perioperative variables for general surgical procedures. This study, therefore, aimed to evaluate the occurrence, determinants and outcome of AKI among children undergoing general (non-cardiac) surgery.

\section{Methods}

This was a prospective cohort study of patients aged 0 to 15 years who had general (non-cardiac) surgery between August 2016 and February 2018 at the University College Hospital, Ibadan, Nigeria. Following ethical approval from the Institution's Ethics Review Board, consent was obtained from parents and assent from consecutive children who were admitted for either elective or emergency general surgical procedure that was planned to last over 30 min and required at least three nights hospital stay. A minimum of three nights was selected so there could be accurate recordings of urinary output and estimation of serum creatinine whilst on admission. Information was obtained with the aid of a structured proforma on biodata, presenting clinical features, duration of illness, indication, and nature of surgery as well as preoperative and intraoperative risk factors for AKI. This study formed part of an epidemiological study of AKI in the hospital. The Kidney Disease: Improving Global Outcomes (KDIGO) guidelines were used to define AKI [13]. Acute kidney injury was considered present when the serum creatinine increased by at least $0.3 \mathrm{mg} / \mathrm{dL}(26.5 \mu \mathrm{mol} / \mathrm{L})$ within $48 \mathrm{~h}$ or increase in serum creatinine to $>1.5$ times the baseline value that is known or presumed to have occurred within the prior 7 days or urine volume $<0.5 \mathrm{~mL} / \mathrm{kg} / \mathrm{h}$ for $6 \mathrm{~h}[13,14]$. Since the patients admitted for emergency surgery did not have serum creatinine within the 7 days prior to the admission, the serum creatinine at admission was used as the baseline for comparison in all the patients. AKI was defined either using the creatinine values or oliguria; within $24 \mathrm{~h}$ of surgery and cumulatively over the first 7 days after surgery. Estimated glomerular filtration rate
(eGFR) was determined using the bedside Schwartz formula among neonates and infants (eGFR $=0.45 \times$ height $/$ serum creatinine) and older children (eGFR $=0.55 \times$ height/serum creatinine) [15].

Preoperatively, the patients were treated according to the hospital protocol for surgical patients; they were resuscitated with intravenous fluids before surgery if they were admitted in emergencies. Patients for elective surgery were optimised on outpatient basis before admission for surgery. Venous blood samples were collected preoperatively and analysed for serum electrolytes, blood urea and creatinine and full blood count. Spot urine samples were obtained for 10-point dipstick urinalysis.

The patients had surgery under general anaesthesia with maintenance and protection of the airway. They all had multi-parameter monitoring whilst under anaesthesia as well as urethral catheterisation. The final blood pressure reading in the induction room of the operative theatre suite was recorded as the preoperative blood pressure using automated sphygmomanometer attached to a multi-parameter monitor. The same monitor was used for all the patients and elevated blood pressure defined as systolic blood pressure that is above $95 \%$ of expected value for age, sex and height [16]. Preoperative anaemia was determined in accordance with the guidelines of the World Health Organisation using haemoglobin concentrations as specified for age and gender [17]. Sepsis was defined as systemic inflammatory response syndrome (SIRS) in the presence of suspected or microbiologically confirmed infection. Presence of SIRS was categorised according to the International Paediatric Sepsis Consensus Conference using the following parameters: core temperature $>38.5^{\circ} \mathrm{C}$ or $<36^{\circ} \mathrm{C}$; tachycardia or bradycardia; tachypnea and leukocytosis or leukopenia as adjusted for age categories of neonates, infants, toddler/preschool, school age children and adolescents/young adults (Table 1) $[18,19]$.

Intraoperative fluid administration, blood losses and urinary output were recorded. Intraoperative events such as hypotension and oliguria were also recorded. The patients were monitored for features of AKI postoperatively until discharged or within 30 days of surgery. Blood samples were taken for serum electrolytes, blood urea and creatinine estimation at $6 \mathrm{~h}$ and $24 \mathrm{~h}$ of surgery as well as on the third and seventh days after surgery. Serum electrolytes were categorised as abnormal if outside the range of $136-145 \mathrm{mmol} / \mathrm{L}$ for sodium, $3.5-5.0$ $\mathrm{mmol} / \mathrm{L}(3.5-6.0 \mathrm{mmol} / \mathrm{L}$ in the first eight weeks of life) for potassium, $95-105 \mathrm{mmol} / \mathrm{L}$ for chloride and $21-30$ $\mathrm{mmol} / \mathrm{L}$ for bicarbonate. Urinary output was recorded hourly until the urinary catheter was removed when the patients became clinically stable and urinary output was normal. The patients were followed up in the outpatients' clinic for at least 3 months and had serum creatinine estimation 30 days after surgery. Excluded from the 
Table 1 Cut off points used in categorisation of the patients

\begin{tabular}{|c|c|c|c|c|c|c|}
\hline & Newborn & Neonate & Infant & Toddler & School age & Adolescents \\
\hline Haemoglobin estimation (anaemia)—based on age $(\mathrm{g} / \mathrm{L}$ ) & Nomogram use & & 110 & 110 & 115 & 120 \\
\hline Leukocyte count $\left(\times 10^{3} / \mathrm{mm}^{3}\right.$ & $>17.5$ or $<5$ & $>17.5$ or $<5$ & $>17.5$ or $<5$ & $>15.5$ or $<6$ & $>15.5$ or $<6$ & $>11.0$ or \\
\hline Tachycardia (heart rate/min) & 180 & 180 & 160 & 140 & 120 & 100 \\
\hline Blood pressure & \multicolumn{6}{|c|}{ Nomogram used_-systolic blood pressure for sex, age and height } \\
\hline Tachypnea (respiration/min) & 60 & 40 & 34 & 30 & 30 & 25 \\
\hline
\end{tabular}

study were patients who were re-operated following an initial surgery and patients who had surgery for obstructive uropathy.

Data obtained were analysed using SPSS version 21 (IBM; Armonk, New York). Univariate analysis was conducted and summarised using means and standard deviation or medians and ranges for skewed data. Categorical variables were described using proportions and percentages. Continuous variables were dichotomized according to their median values and converted into categorical variables. Test of association between categorical variables was performed using chi-square statistics. Mann-Whitney $U$ was used to test for association between continuous variables. Variables that were significant at $20 \%$ were entered into a multinomial logistic regression model to identify predictors of AKI among risk factors evaluated. The $p$ value for statistical significance was set at $<0.05$.

\section{Results}

A total of 93 patients were recruited into the study with age ranging from 3 days to 15 years; median age was 4 years. There were $67(72.0 \%)$ males, $6(6.5 \%)$ patients were within the first 28 days of birth and $25(26.9 \%)$ were less than 12 months of age. The majority $(81,87.1 \%)$ were from Yoruba mothers (the predominant ethnic group in the city).

The condition necessitating the surgery was congenital in $35(37.6 \%)$ and involved the gastrointestinal tract in $52(55.9 \%)$ patients. In $37(39.8 \%)$ patients, the surgery was on account of an inflammatory process and 24 (25.8\%) had features of sepsis preoperatively. The surgery was an emergency in $43(46.2 \%)$ patients. The commonest procedures performed were laparotomies for various conditions 49 (52.7\%), urethroplasties for hypospadias $22(23.7 \%)$ and appendicectomies 7 (7.5\%). A total of $42(45.2 \%)$ patients had an electrolyte abnormality preoperatively. The median duration of surgery was $87 \mathrm{~min}$ (range of $30 \mathrm{~min}$ to $210 \mathrm{~min}$ ). The duration of anaesthesia ranged from $40 \mathrm{~min}$ to $295 \mathrm{~min}$ (median of $112 \mathrm{~min}$ ). The estimated blood loss at surgery was $5 \mathrm{ml}$ to $800 \mathrm{ml}$ (median of $50 \mathrm{ml}$ ). The estimated blood loss per kilogramme body weight was 0.14 to $28.07 \mathrm{ml} / \mathrm{kg}$ with a median of $2.78 \mathrm{ml} / \mathrm{kg}$. The median baseline estimated glomerular filtration rate (eGFR) was $72.5 \mathrm{ml} /$ $\mathrm{min} / 1.73 \mathrm{~m}^{2}\left(\right.$ range $\left.=17.6-138.8 \mathrm{ml} / \mathrm{min} / 1.73 \mathrm{~m}^{2}\right)$.
AKI occurred within $24 \mathrm{~h}$ of surgery in 32 (34.4\%) patients - 22 (23.7\%) using creatinine values only and 11 (11.8\%) using urinary output alone. Cumulatively, AKI occurred within 7 days of surgery in 33 (35.5\%) patients. There was no significant difference between the baseline eGFR of patients who developed AKI and those who did not have AKI, $p=0.239$ (Table 2).

The AKI was stage I in 21 (63.6\%), stage II in 10 (30.3\%) and stage III in $2(6.1 \%)$ patients. All but 3 of the 33 patients had recovered from the AKI, with serum creatinine at or below baseline and within normal limits as well as normal urinary output by the end of the first week. The median baseline eGFR was lowest in patients with AKI stage III $\quad\left(\right.$ median $=54.0 \mathrm{ml} / \mathrm{min} / 1.73 \mathrm{~m}^{2} ; \quad$ range $=52.1-$ $55.8 \mathrm{ml} / \mathrm{min} / 1.73 \mathrm{~m}^{2}$ ) compared to stage II (median $=70.0$ $\mathrm{ml} / \mathrm{min} / 1.73 \mathrm{~m}^{2} ; \quad$ range $\left.=19.6-95.6 \mathrm{ml} / \mathrm{min} / 1.73 \mathrm{~m}^{2}\right)$ and stage I $\left(\right.$ median $=86.7 \mathrm{ml} / \mathrm{min} / 1.73 \mathrm{~m}^{2} ;$ range $=44.1-138.8$ $\left.\mathrm{ml} / \mathrm{min} / 1.73 \mathrm{~m}^{2}\right), p=0.067$.

The proportion of patients who had sepsis before surgery and developed AKI within 7 days was higher than the proportion of those who did not have sepsis before surgery and developed AKI over the same period (58.3\% vs. $27.5 \%, p=0.007)$. There were no statistically significant associations between other baseline preoperative (Table 2 and Table 3 ) or intraoperative variables (Table 4) and occurrence of AKI within 7 days of surgery.

Patients who had sepsis before surgery were nearly four times as likely as those without sepsis to develop AKI within 7 days of surgery $(\mathrm{OR}=3.52$, 95\% CI 1.21, $10.20, p=0.021)$. The model was evaluated to be a good fit (Hosmer-Lemeshow: $\chi^{2}=5.237, \mathrm{DF}=7, p=0.631$ ). Elevated preoperative blood pressure, nature of surgery done and the estimated blood loss were not significant predictors of AKI (Table 5).

The length of hospital stay post operation was 5 to 82 days, with a median of 14 days. There were no differences in the length of stay after surgery and eGFR at 3 months between patients who had AKI and those who did not have AKI (Table 6). At the end of 3 months follow-up, 87 (93.5\%) were alive, 4 (4.3\%) dead and 2 (2.2\%) discharged against medical advice thus were not available for follow-up. All four died on admission, including three that had not recovered from the AKI (two had multi-organ failure and the third died from sepsis) and one who died from sepsis. Crude mortality rate was 
Table 2 Association between median (and range) baseline characteristics and cumulative AKI within 7 days of surgery

\begin{tabular}{llll}
\hline Variable & AKl & No AKl & $p$ value \\
\hline Age $($ months) & $72.0(0.4-168.0)$ & $56.0(0.0-180.0)$ & 0.506 \\
Heart rate $(/ \mathrm{min})$ & $106(66-150)$ & $116(68-160)$ & 0.723 \\
Respiratory rate $(/ \mathrm{min})$ & $28(20-86)$ & $32(16-60)$ & 0.402 \\
Systolic blood pressure $(\mathrm{mmHg})$ & $101.5(86-140)$ & $100.0(60-130)$ & 0.126 \\
Haemoglobin $(\mathrm{g} / \mathrm{L})$ & $11.0(7.0-14.3)$ & $11.3(6.1-18.7)$ & 0.495 \\
Leukocyte $\left(\times 10^{3} / \mathrm{mm}^{3}\right)$ & $9.4(3.0-24.0)$ & $9.2(2-26.6)$ & 0.919 \\
Serum sodium $(\mathrm{mmol} / \mathrm{L})$ & $135(121-143)$ & $136(103-146)$ & 0.551 \\
Serum potassium $(\mathrm{mmol} / \mathrm{L})$ & $3.9(2.2-6.6)$ & $3.9(1.5-5.5)$ & 0.875 \\
Serum chloride $(\mathrm{mmol} / \mathrm{L})$ & $101(88-130)$ & $102(87-116)$ & 0.633 \\
Serum bicarbonate $(\mathrm{mmol} / \mathrm{L})$ & $19(10-44)$ & $19(7-28)$ & 0.906 \\
eGFR $\left(\mathrm{ml} / \mathrm{min} / 1.73 \mathrm{~m}^{2}\right)$ & $71.0(17.6-138.8)$ & $81.0(19.6-142.0)$ & 0.239 \\
\hline
\end{tabular}

$A K I$, acute kidney injury; eGFR, estimated glomerular filtration rate

Table 3 Association between preoperative parameters and cumulative AKI within 7 days of surgery

\begin{tabular}{|c|c|c|c|c|c|c|c|c|c|c|c|}
\hline Variable & AKI & No AKI & Total & $x^{2}$ & $p$ value & & & & & & \\
\hline \multicolumn{12}{|l|}{ Age group } \\
\hline Infants & $8(32.0)$ & $17(68.0)$ & 25 & \multirow[t]{2}{*}{0.181} & \multirow[t]{2}{*}{0.670} & & & & & & \\
\hline Older child & $25(36.8)$ & $43(63.2)$ & 68 & & & & & & & & \\
\hline \multicolumn{12}{|l|}{ Indication for surgery } \\
\hline Congenital disease & $12(34.3)$ & $23(65.7)$ & 35 & \multirow[t]{2}{*}{0.035} & \multirow[t]{2}{*}{0.851} & & & & & & \\
\hline Acquired disease & $21(36.2)$ & $37(63.8)$ & 58 & & & & & & & & \\
\hline \multicolumn{6}{|l|}{ System affected } & \multirow{2}{*}{\multicolumn{6}{|c|}{$\begin{array}{l}\text { Table } 4 \text { Association between operative variables and } \\
\text { cumulative AKI within } 7 \text { days of surgery }\end{array}$}} \\
\hline Gastrointestinal tract & $20(38.5)$ & $32(61.5)$ & 52 & \multirow[t]{2}{*}{0.457} & \multirow[t]{2}{*}{0.499} & & & & & & \\
\hline Other systems & $13(31.7)$ & $28(68.3)$ & 41 & & & Variable & AKI & No AKI & Total & $x^{2}$ & $p$ value \\
\hline \multicolumn{6}{|l|}{ Preoperative sepsis } & \multicolumn{6}{|l|}{ Type of surgery } \\
\hline Yes & $14(58.3)$ & $10(41.7)$ & 24 & \multirow[t]{2}{*}{7.377} & \multirow[t]{2}{*}{${ }^{*} 0.007$} & Emergency surgery & $16(37.2)$ & $27(62.8)$ & 43 & \multirow[t]{2}{*}{0.104} & \multirow[t]{2}{*}{0.747} \\
\hline No & $19(27.5)$ & $50(72.5)$ & 69 & & & Elective surgery & $17(34.0)$ & $33(66.0)$ & 50 & & \\
\hline \multicolumn{6}{|l|}{ Preoperative leucocytosis } & \multicolumn{6}{|l|}{ Surgery done } \\
\hline Yes & $7(41.2)$ & $10(58.8)$ & 17 & 0.294 & 0.587 & Laparotomy & $21(42.9)$ & $28(57.1)$ & 49 & 2.460 & 0.117 \\
\hline No & $26(34.2)$ & $50(65.8)$ & 76 & & & Other operations & $12(27.3)$ & $32(72.7)$ & 44 & & \\
\hline \multicolumn{6}{|l|}{ Preoperative anaemia } & \multicolumn{6}{|l|}{ Duration of surgery } \\
\hline Yes & $6(33.3)$ & $12(66.7)$ & 18 & \multirow[t]{2}{*}{0.045} & \multirow[t]{2}{*}{0.832} & $\geq 87 \min$ & $16(37.2)$ & $27(62.8)$ & 43 & \multirow[t]{2}{*}{0.104} & \multirow[t]{2}{*}{0.747} \\
\hline No & $27(36.0)$ & $48(64.0)$ & 75 & & & $<87 \min$ & $17(34.0)$ & $33(66.0)$ & 50 & & \\
\hline \multicolumn{6}{|l|}{ Preoperative tachycardia } & \multicolumn{6}{|l|}{ Duration of anaesthesia } \\
\hline Yes & $15(33.3)$ & $30(66.7)$ & 45 & \multirow[t]{3}{*}{0.176} & \multirow[t]{3}{*}{0.675} & $\geq 112 \mathrm{~min}$ & $17(35.4)$ & $31(64.6)$ & 48 & 0.001 & 0.989 \\
\hline No & $18(37.5)$ & $30(62.5)$ & 48 & & & $<112 \mathrm{~min}$ & $16(356)$ & & & & \\
\hline Elevated preoperative BP & & & & & & $<112 \mathrm{~min}$ & $10(35.0)$ & $29(64.4)$ & 45 & & \\
\hline Yes & $12(48.0)$ & $13(52.0)$ & 25 & 2.340 & 0.126 & $\mathrm{EBL}$ & & & & & \\
\hline No & $21(30.9)$ & $47(69.1)$ & 68 & & & $\geq 2.78 \mathrm{ml} / \mathrm{kg}$ & $20(43.5)$ & $26(56.5)$ & 46 & 2.541 & 0.111 \\
\hline Electrolyte abnormality p & operation ${ }^{\#}$ & & & & & $<2.78 \mathrm{ml} / \mathrm{kg}$ & $13(27.7)$ & $34(72.3)$ & 47 & & \\
\hline Yes & $17(40.5)$ & $25(59.5)$ & 42 & 0.834 & 0.361 & Intraop blood transfusi & & & & & \\
\hline No & $16(31.4)$ & 35 (68.6) & 51 & & & Yes - transfused & $10(45.5)$ & $12(54.5)$ & 22 & 1.251 & 0.263 \\
\hline $\begin{array}{l}\text { AKI, acute kidney injury; } \\
{ }^{*} \text { Statistically significant }\end{array}$ & 14 & & & & & No transfusion & $23(32.4)$ & 48 (67.6) & 71 & & \\
\hline
\end{tabular}

\#Serum electrolytes assayed were sodium (136-145 mmol/L), potassium (3.5-

$5.0 \mathrm{mmol} / \mathrm{L} ; 3.5-6.0 \mathrm{mmol} / \mathrm{L}$ in first 8 weeks of life), chloride $(95-105 \mathrm{mmol} / \mathrm{L})$

AKI, acute kidney injury; $\chi^{2}$, chi-square; $E B L$, estimated blood loss;

Intraop, intraoperative

and bicarbonate $(21-30 \mathrm{mmol} / \mathrm{L})$ 
Table $\mathbf{5}$ Logistic regression analysis of the relationship between preoperative and intraoperative variables and 7-day cumulative AKI occurrence

\begin{tabular}{llll}
\hline Variable & Categories of variable & OR & $95 \% \mathrm{Cl}$ \\
\hline Preoperative sepsis & Yes & 3.52 & $1.21-10.20$ \\
& No & & $0.021^{*}$ \\
Elevated preoperative BP & Yes & 2.49 & $0.91-6.76$ \\
& No & 1.22 & $0.43-3.48$ \\
Surgery done & Laparotomy & & 0.074 \\
EBL & Other surgery & 1.40 & $0.26-2.02$ \\
& $\geq 2.78 \mathrm{ml} / \mathrm{kg}$ & & 0.529 \\
& $<2.78 \mathrm{ml} / \mathrm{kg}$ & &
\end{tabular}

*Statistically significant; reference category on logistic regression = AKI occurred within 7 days of surgery; EBL, estimated blood loss

12.1\% among patients who had AKI whereas no mortality was recorded among those without AKI, $p=0.014$ (Table 6). Mortality was recorded in both patients with AKI stage III compared with none of the 10 with stage 2 and in 2 of the $21(9.5 \%)$ with stage I $(p=0.002)$.

\section{Discussion}

This prospective cohort study evaluated the occurrence of AKI among children who underwent general (non-cardiac) surgery conducted under general anaesthesia in a tertiary hospital in sub-Saharan Africa. The study also evaluated the outcome of care of the patients and identified determinants of AKI among perioperative variables evaluated.

The incidence of AKI in this cohort was $34.4 \%$ within 24 h of surgery. Cumulatively, over the first 7 days of surgery, $35.5 \%$ of the patients developed AKI. These figures are closer to the lower end of the range of incidences reported from perioperative AKI secondary to cardiac or cardiopulmonary surgery $[6,10,20,21]$. The figures are also much higher than $3.13 \%$ that was reported among children from a wide range of paediatric wards, including paediatric surgery ward, intensive care unit, paediatric nephrology and hypertension units at Ile Ife, Nigeria, which is located close to where the study took place [7]. The incidence may have been higher because the study was restricted to a largely homogenous group of patients who had surgery compared to the study conducted at Ile Ife where the numerator was more heterogeneous and $73 \%$ of the AKI cases were community-acquired. Nearly half of the hospital-acquired AKI in that study was due to nephrotoxicity [7]. Furthermore, the serum creatinine criterion of the Acute Kidney Injury Network (AKIN) was used to determine AKI compared to the KDIGO criteria.

The incidence of AKI at $24 \mathrm{~h}$ of surgery of $34.4 \%$ may appear quite high to most paediatric general surgeons, and there are no comparative data with similar spectrum of cases. This contrasts with the incidence of AKI of $11.8 \%$ within $24 \mathrm{~h}$ of surgery if oliguria alone or $23.7 \%$ if serum creatinine criteria alone was used to define acute kidney injury. The differences between the incidences using the two parameters underscore the possibility of under-diagnosis of AKI perioperatively in those units where inadequate urine output is solely utilised. It is important to note that using the KDIGO criteria, AKI was diagnosed even when the perioperative serum creatinine remained below the threshold of $1 \mathrm{mg} / \mathrm{dL}$ as long as one of the criteria was fulfilled. Adding oliguria to an initial evaluation based on creatinine parameter from the KDIGO criteria had been shown to raise the incidence of AKI from 20 to $38 \%$ among the same group of patients [22]. The use of single rather than multiple parameters from other AKI assessment methods has equally been shown to underscore the incidence and severity of AKI [4, 23, 24].

Sepsis was the only significant determinant of perioperative AKI in the study. Sepsis was associated with a fourfold odds of development of perioperative AKI following general paediatric surgery. Sepsis on its own is a major cause of AKI in children $[25,26]$. It has been shown by other authors to predict the occurrence of AKI [13] or mortality from AKI [27]. Sepsis has been shown in experimental animals to lead to renal hypoperfusion and reduction in renal blood flow [26,

Table 6 Comparative outcome in patients with or without acute kidney injuries

\begin{tabular}{llll}
\hline Variable & AKl & No AKl & $p$ value \\
\hline Length of hospital stay (days) ${ }^{\#}$ & $15(5-38)$ & $14(5-82)$ & 0.499 \\
eGFR at 3 months $\left(\mathrm{ml} / \mathrm{min} / 1.73 \mathrm{~m}^{2}\right)^{\#}$ & $77.0(38.8-157.7)$ & $84.0(60.4-119.4)$ & 0.443 \\
30 -day mortality (\%) & $12.1 \%(4 / 33)$ & $0 \%(0 / 58)$ & $* 0.014$ \\
\hline
\end{tabular}

AKI, acute kidney injury; eGFR, estimated glomerular filtration rate,

"Median value (range)

*Statistically significant 
28]. The interplay of inflammation, oxidative stress, microvascular dysfunction and tubular adaptation to sepsis has been suggested as a possible mechanism of sepsis-induced AKI [29]. Therefore, it is important to pay close attention to the treatment of sepsis, in low- to middle-income settings, considering that one quarter of the patients had preoperative sepsis in this study. Delayed presentation could have contributed to the extent of sepsis seen among the patients [30].

The outcome of care of patients with AKI was relatively good with AKI resolved at the end of 7 days in all but four patients, i.e., $88 \%$. This could be because $94 \%$ of the AKI seen in this group of patients was stage I or II, coupled with early review by the nephrologists and prompt fluid resuscitation and rationale use of antibiotics in those patients with sepsis. The outcome of care was, however, worse among patients who developed AKI when compared to those without AKI; mortality was recorded only among patients who developed AKI. Similar findings were reported by Riyuzo et al. [27] who studied 77 children with AKI in the Paediatric Intensive Care Unit over a 5 -year period and found that $73 \%$ of the patients with AKI recovered over the first week of diagnosis and the overall mortality was related to the severity of renal dysfunction. Others have reported similar effect of AKI on postoperative mortality in children [31-34]. The findings suggest that adequate fluid therapy and use of diuretics/inotropes where indicated, as well as appropriate treatment of preoperative sepsis are measures to prevent AKI in children undergoing general surgery. The impact of intervention by the nephrologists was most evident in patients with KDIGO stage II AKI in this study as there was no mortality in this group. Patients who have stage III AKI, on the other hand, did not survive in the present study.

A limitation of this study is the inability to stratify patients according to age grouping to explore for differences in relation to AKI among neonates, infants and older children. A larger sample size or a multi-centre study will be able to address this defect. Being a novel enquiry into perioperative AKI in patients who underwent paediatric general (non-cardiac) surgery, other studies can elaborate on the present research.

In conclusion, perioperative AKI occurred in $35.5 \%$ of children who underwent general (non-cardiac) surgery. Patients who had sepsis before surgery were four times more likely than others to develop AKI. Mortality, documented only in patients who had AKI, was worst in patients with severe AKI; this could be prevented with prompt treatment of sepsis and adequacy of fluid resuscitation perioperatively.

\section{Abbreviations}

AKI: Acute kidney injury; AKIN: Acute Kidney Injury Network; eGFR: Estimated glomerular filtration rate; KDIGO: The Kidney Disease: Improving Global Outcomes; SIRS: Systemic inflammatory response syndrome

\section{Acknowledgements}

The authors acknowledge Mr. Sakiru Najeem who facilitated recruitment of patients for the study.

\section{Funding}

The International Society of Nephrology (Clinical Research and Prevention Program Proposal 04-057) provided funds for the study. The International Society of Nephrology was not involved at any stage of the research, other than provision of funds for the study.

\section{Availability of data and materials}

The datasets used and/or analysed during the current study are available from the corresponding author on reasonable request.

\section{Authors' contributions}

TAL and YRR conceptualised the study and wrote major parts of the proposal. All the authors contributed to the proposal. YRR secured the grant for the study. TAL, YRR and SOA designed the data collection form. TAL and YRR coordinated the data collection. TAL wrote the first draft of the manuscript. All the authors contributed to the manuscript and approved the final version of the manuscript.

\section{Authors' information}

TAL, OOO and DIO are paediatric surgeons; YRR, SAA and BLS are nephrologists; ADA and AOA are paediatric nephrologists; AFA and OOA are general surgeons and TA is an anaesthetist at the same hospital. They are all members of the multidisciplinary team working on acute kidney injury at the hospital.

\section{Ethics approval and consent to participate}

Ethical approval for the conduct of the study was obtained from the joint University of Ibadan/University College Hospital Ethics Research Committee. Consent was obtained from the parents and assent from the children before inclusion in the study.

Consent for publication

Not applicable.

\section{Competing interests}

The authors declare that they have no competing interests.

\section{Publisher's Note}

Springer Nature remains neutral with regard to jurisdictional claims in published maps and institutional affiliations.

\section{Author details}

'Division of Paediatric Surgery, Department of Surgery, College of Medicine, University of Ibadan, PMB 5017, Ibadan 200212, Nigeria. ${ }^{2}$ Nephrology Unit, Department of Medicine, College of Medicine, University of Ibadan, PMB 5017, Ibadan 200212, Nigeria. ${ }^{3}$ Paediatric Nephrology Unit, Department of Paediatrics, College of Medicine, University of Ibadan, PMB 5017, Ibadan 200212, Nigeria. ${ }^{4}$ Department of Surgery, College of Medicine, University of Ibadan, PMB 5017, Ibadan 200212, Nigeria. ${ }^{5}$ Department of Anaesthesia,

College of Medicine, University of Ibadan, PMB 5017, Ibadan 200212, Nigeria.

Received: 28 November 2018 Accepted: 11 April 2019

Published online: 27 April 2019

\section{References}

1. Ostermann M, Chang RW. Challenges of defining acute kidney injury. QJM. 2011;104(3):237-43. https://doi.org/10.1093/qjmed/hcq185.

2. Susantitaphong P, Cruz DN, Cerda J, Abulfaraj M, Alqahtani F, Koulouridis I, Jaber BL, Acute Kidney Injury Advisory Group of the American Society of N. World incidence of AKl: a meta-analysis. Clin J Am Soc Nephrol. 2013;8(9): 1482-93. https://doi.org/10.2215/CJN.00710113.

3. Halle MP, Lapsap CT, Barla E, Fouda H, Djantio H, Moudze BK, Akazong CA Priso EB. Epidemiology and outcomes of children with renal failure in the pediatric ward of a tertiary hospital in Cameroon. BMC Pediatr. 2017;17(1): 202. https://doi.org/10.1186/s12887-017-0955-0.

4. Macedo E, Cerda J, Hingorani S, Hou J, Bagga A, Burdmann EA, Rocco VM, Mehta LR. Recognition and management of acute kidney injury in children: 
the ISN Oby25 Global Snapshot study. PLoS One. 2018;13(5):e0196586. https://doi.org/10.1371/journal.pone.0196586.

5. Sutherland SM, Byrnes JJ, Kothari M, Longhurst CA, Dutta S, Garcia P, Goldstein SL. AKI in hospitalized children: comparing the pRIFLE, AKIN, and KDIGO definitions. Clin J Am Soc Nephrol. 2015;10(4):554-61. https://doi. org/10.2215/CJN.01900214.

6. Olowu WA, Niang A, Osafo C, Ashuntantang G, Arogundade FA, Porter J, Naicker S, Luyckx VA. Outcomes of acute kidney injury in children and adults in sub-Saharan Africa: a systematic review. Lancet Glob Health. 2016; 4(4):e242-50. https://doi.org/10.1016/S2214-109X(15)00322-8.

7. Olowu WA, Adefehinti O, Bisiriyu AL. Hospital-acquired acute kidney injury in critically ill children and adolescents. Saudi J Kidney Dis Transpl. 2012;23(1):68-77.

8. Butler EK, Tran TM, Nagarajan N, Canner J, Fuller AT, Kushner A, Haglund MM, Smith ER, Group SCR. Epidemiology of pediatric surgical needs in lowincome countries. PLoS One. 2017;12(3):e0170968. https://doi.org/10.1371/ journal.pone.0170968.

9. Gupta S, Groen RS, Kyamanywa P, Ameh EA, Labib M, Clarke DL, Donkor P, Derbew M, Sani R, Kamara TB, Shrestha S, Nwomeh BC, Wren SM, Price RR, Kushner AL. Surgical care needs of low-resource populations: an estimate of the prevalence of surgically treatable conditions and avoidable deaths in 48 countries. Lancet. 2015;385(Suppl 2):S1. https://doi.org/10.1016/S01406736(15)60796-6.

10. Yuan S-M (In Press) Acute kidney injury after pediatric cardiac surgery. Pediatr Neonatol. https://doi.org/10.1016/j.pedneo.2018.03.007

11. Lawal TA, Adeleye AO, Ayede Al, Ogundoyin OO, Olulana DI, Olusanya AA, et al. Congenital paediatric surgical cases in Ibadan: patterns and associated malformations. Afr J Med Med Sci. 2017;46:49-55.

12. Grams ME, Sang Y, Coresh J, Ballew S, Matsushita K, Molnar MZ, Szabo Z, Kalantar-Zadeh K, Kovesdy CP. Acute kidney injury after major surgery: a retrospective analysis of veterans health administration data. Am J Kidney Dis. 2016;67(6):872-80.

13. Raji YR, Ajayi SO, Ademola AF, Lawal TA, Ayandipo OO, Adigun T, Salako B. Acute kidney injury among adult patients undergoing major surgery in a tertiary hospital in Nigeria. Clin Kidney J. 2018;11(4):443-9. https://doi.org/10.1093/ckj/sfx144.

14. Khwaja A. KDIGO clinical practice guidelines for acute kidney injury. Nephron Clinical Practice. 2012;120(4):c179-84.

15. Muhari-Stark E, Burckart GJ. Glomerular filtration rate estimation formulas for pediatric and neonatal use. J Pediatr Pharmacol Ther. 2018;23(6):424-31. https://doi.org/10.5863/1551-6776-23.6.424.

16. Jobe M, Agbla SC, Prentice AM, Hennig BJ. High blood pressure and associated risk factors as indicator of preclinical hypertension in rural West Africa: a focus on children and adolescents in the Gambia. Medicine (Baltimore). 2017;96(13):e6170. https://doi.org/10.1097/MD. 0000000000006170.

17. Ngesa O, Mwambi H. Prevalence and risk factors of anaemia among children aged between 6 months and 14 years in Kenya. PLoS One. 2014; 9(11):e113756. https://doi.org/10.1371/journal.pone.0113756.

18. Goldstein B, Giroir B, Randolph A. International consensus conference on pediatric Sepsis. Pediatr Crit Care Med. 2005;6(1):2-8. https://doi.org/10. 1097/01.PCC.0000149131.72248.E6.

19. Wiens MO, Kumbakumba E, Kissoon N, Ansermino JM, Ndamira A, Larson CP. Pediatric sepsis in the developing world: challenges in defining sepsis and issues in post-discharge mortality. Clin Epidemiol. 2012;4:319-25. https://doi.org/10.2147/CLEP.S35693.

20. Park SK, Hur M, Kim E, Kim WH, Park JB, Kim Y, Yang JH, Jun TG, Kim CS. Risk factors for acute kidney injury after congenital cardiac surgery in infants and children: a retrospective observational study. PLoS One. 2016;11(11): e0166328. https://doi.org/10.1371/journal.pone.0166328.

21. Zappitelli M, Greenberg JH, Coca SG, Krawczeski CD, Li S, Thiessen-Philbrook HR, Bennett MR, Devarajan P, Parikh CR, Translational Research Investigating Biomarker Endpoints in Acute Kidney Injury C. Association of definition of acute kidney injury by cystatin $\mathrm{C}$ rise with biomarkers and clinical outcomes in children undergoing cardiac surgery. JAMA Pediatr. 2015;169(6):583-91. https://doi.org/10.1001/jamapediatrics.2015.54.

22. Koeze J, Keus F, Dieperink W, van der Horst I, Zijlstra J, Van Meurs M. Incidence, timing and outcome of AKI in critically ill patients varies with the definition used and the addition of urine output criteria. BMC Nephrol. 2017;18(1):70

23. Lagny MG, Jouret F, Koch JN, Blaffart F, Donneau AF, Albert A, Roediger L, Krzesinski JM, Defraigne JO. Incidence and outcomes of acute kidney injury after cardiac surgery using either criteria of the RIFLE classification. BMC Nephrol. 2015;16:76. https://doi.org/10.1186/s12882-015-0066-9.

24. Wlodzimirow KA, Abu-Hanna A, Slabbekoorn M, Chamuleau RA, Schultz MJ, Bouman CS. A comparison of RIFLE with and without urine output criteria for acute kidney injury in critically ill patients. Crit Care. 2012;16(5):R200. https://doi.org/10.1186/cc11808.

25. Abdelraheem M, Ali E-T, Osman R, Ellidir R, Bushara A, Hussein R, Elgailany S, Bakhit $Y$, Karrar M, Watson A. Outcome of acute kidney injury in Sudanese children - an experience from a sub-Saharan African unit. Perit Dial Int. 2014;2013:00082.

26. Seely KA, Holthoff JH, Burns ST, Wang Z, Thakali KM, Gokden N, Rhee SW, Mayeux PR. Hemodynamic changes in the kidney in a pediatric rat model of sepsis-induced acute kidney injury. Am J Physiol Renal Physiol. 2011; 301(1):F209-17. https://doi.org/10.1152/ajprenal.00687.2010.

27. Riyuzo MC, Silveira LV, Macedo CS, Fioretto JR. Predictive factors of mortality in pediatric patients with acute renal injury associated with sepsis. J Pediatr. 2017:93(1):28-34. https://doi.org/10.1016/.j.jped.2016.04.006.

28. Basile DP, Anderson MD, Sutton TA. Pathophysiology of acute kidney injury. Compr Physiol. 2012;2(2):1303-53. https://doi.org/10.1002/cphy.c110041.

29. Gomez H, Ince C, De Backer D, Pickkers P, Payen D, Hotchkiss J, Kellum JA. A unified theory of sepsis-induced acute kidney injury: inflammation, microcirculatory dysfunction, bioenergetics, and the tubular cell adaptation to injury. Shock. 2014;41(1):3-11. https://doi.org/10.1097/SHK. 0000000000000052

30. Ogundoyin OO, Olulana DI, Lawal TA. Childhood intussusception: impact of delay in presentation in a developing country. Afr J Paediatr Surg. 2016; 13(4):166-9. https://doi.org/10.4103/0189-6725.194665.

31. Blinder JJ, Goldstein SL, Lee V-V, Baycroft A, Fraser CD, Nelson D, Jefferies JL. Congenital heart surgery in infants: effects of acute kidney injury on outcomes. J Thorac Cardiovasc Surg. 2012;143(2):368-74.

32. Esch JJ, Salvin JM, Thiagarajan RR, Pedro J, Rajagopal SK. Acute kidney injury after Fontan completion: risk factors and outcomes. J Thorac Cardiovasc Surg. 2015;150(1):190-7.

33. Morgan CJ, Zappitelli M, Robertson CM, Alton GY, Sauve RS, Joffe AR, Ross DB, Rebeyka IM, Group WCCPTF-U. Risk factors for and outcomes of acute kidney injury in neonates undergoing complex cardiac surgery. J Pediatr. 2013:162(1):120-7 e121.

34. Tóth R, Breuer T, Cserép Z, Lex D, Fazekas L, Sápi E, Szatmári A, Gál J, Székely A. Acute kidney injury is associated with higher morbidity and resource utilization in pediatric patients undergoing heart surgery. Ann Thorac Surg. 2012;93(6):1984-90.

Ready to submit your research? Choose BMC and benefit from

- fast, convenient online submission

- thorough peer review by experienced researchers in your field

- rapid publication on acceptance

- support for research data, including large and complex data types

- gold Open Access which fosters wider collaboration and increased citations

- maximum visibility for your research: over $100 \mathrm{M}$ website views per year

At $\mathrm{BMC}$, research is always in progress.

Learn more biomedcentral.com/submissions 